\title{
First measurements of methyl tert-butyl ether (MTBE) in the ambient air in San Jose, Costa Rica
}

\author{
G. Esquivel-Hernández ${ }^{1}$, J. P. Sibaja-Brenes ${ }^{1}$, \\ J. C. Mora-Barrantes ${ }^{2}$ \& J. Valdés-González ${ }^{1}$ \\ ${ }^{1}$ Laboratorio de Química de la Atmósfera, Escuela de Química, \\ Universidad Nacional, Costa Rica \\ ${ }^{2}$ Escuela de Química, Universidad Nacional, Costa Rica
}

\begin{abstract}
A great interest has arisen in establishing the impact of organic compounds on human health and air quality, especially those compounds emitted by automotive traffic. Knowledge of urban air pollutant concentrations is essential for the determination of exposure levels. With this information public health problems can be avoided and emissions sources can be identified. MTBE is one of such compound because of its effects both to the environment and to humans. In Costa Rica, as in many other parts of the world, MTBE has been added to gasoline up to $10 \% \mathrm{v} / \mathrm{v}$. This study investigates ambient air concentration of MTBE in San Jose, Costa Rica. Samples were collected during OctoberDecember 2005 using Carbotrap ${ }^{\circledR}$ cartridges and analyzed by thermal desorption combined with capillary gas chromatography. MTBE levels ranged from $<0.1$ to $7.0 \mathrm{ppbv}$, with the highest concentrations observed in the wet season's months (May to November). The highways and industrial areas were identified as MTBE's point sources, both related with vehicle emissions. High levels of MTBE were also found in the vicinity of a gas station. These values represent the first measurements made in a Central American location, but are similar to those reported in other urban areas. The MTBE ambient air levels in San Jose, Costa Rica were not known until this study in 2005.
\end{abstract}

Keywords: GC, MTBE, human health, urban air. 


\section{Introduction}

This work reports on five months' measurements of MTBE in ambient air carried out in San Jose, Costa Rica's capital city. San Jose is located in the centre of the country $\left(9^{\circ} 56^{\prime} \mathrm{N}, 84^{\circ} 5^{\prime} \mathrm{W}\right)$, on a mountain plateau at an elevation of about 1170 m.a.s.l. and has a population of 340,000 people. In Costa Rica, MTBE is used as an additive in gasoline, with an average of $10 \% \mathrm{v} / \mathrm{v}$ and it is used to enhance the gasoline's octane number. Because of its high volatility and aqueous solubility, the hazards caused by environmental emissions of MTBE are of general concern [1]. Among these problems the contamination of drinking water supplies and groundwater reservoirs has been found [2]. It has also been reported that human exposure to vapours of reformulated gasoline may produce headaches, nausea and eye, nose, and throat irritation. Other in vivo toxicological studies have demonstrated cytological anomalies [3, 4]. Measurements in the ambient air of other inorganic pollutants, such as sulphur dioxide, nitrogen oxides, carbon monoxide and particulate matter and volatile organic compounds (VOCs) have been made frequently in the past in San Jose, but MTBE concentrations were not previously measured $[5,6]$. The data presented in this article are of value because of the unique geographic position of Costa Rica and the tropical climatic conditions of Central America, but are also important with respect to future fuel policies and air quality issues in this region.

\section{Experimental}

Sampling was done at two downtown locations; one located in La Uruca, an industrial area, and another in front of National Children Hospital (Hospital), in downtown San Jose. Sampling points were selected according to their distance to heavy traffic locations, i.e., that were closed to streets that bring a large portion of cars, trucks and buses and also near traffic lights and bus stops. Samples were collected $2.5 \mathrm{~m}$ above the ground.

Samples were collected using cartridges filled with Carbotrap ${ }^{\circledR}$, and precision air pumps (A.P. Buck, Florida, USA). The air volumes were in the range from 0.5 to $2.0 \mathrm{~L}$. A total of 152 samples were collected during October-December 2005. Sampling periods of 24 hours were chosen, with hourly samples collected for four days in October and during 15 consecutive days from November to December, samples were collected every six hours. During this last sampling campaign, the sampling intervals were from 12:00 a.m. to 6:00 a.m., 7:00 a.m. to noon, 1:00 p.m. to 6:00 p.m. and 7:00 p.m. to midnight.

In the laboratory, samples were analyzed using thermal desorption combined with gas chromatography on a modified Perkin Elmer Autosystem XL chromatograph (Perkin Elmer Instruments, Massachusetts, USA). VOCs were separated using a DB-1 capillary column, $60 \mathrm{~m}$ long x $0.32 \mathrm{~mm}$ internal diameter x $1.0 \mu \mathrm{m}$ film thickness. VOCs were desorbed onto the cooled column and eluted with helium, raising temperature from $-60^{\circ} \mathrm{C}$ to $200^{\circ} \mathrm{C}$ at $8.5^{\circ} \mathrm{C} \mathrm{min}{ }^{-1}$. Detection was accomplished using a FID detector. Qualitative analysis of MTBE was made based on retention data and comparison with known composition samples. 
Quantitative analysis involved the use of a NIST traceable standard (Pentane 15 ppmv, Scott Specialty Gases, analytical accuracy of $\pm 2 \%$ ) and the use of MTBE gas standards prepared by static dilution. Applied methodology has been previously described by other authors [7-9]. The detection limit of the method was set on $0.1 \mathrm{ppbv}\left(0.4 \mu \mathrm{g} \mathrm{m}^{-3}\right)$ for an air volume of $2.0 \mathrm{~L}$. Samples with values below detection limit were assigned a value of half the detection limit for calculations. Hourly samples and six hour samples were not directly compared, and average MTBE concentrations are used for discussion.

\section{Results and discussion}

Table 1 summarizes ambient concentrations of MTBE measured in downtown locations in San Jose, Costa Rica. In October, MTBE's concentrations were in the range from below 0.1 to $7.0 \mathrm{ppbv}$, with an average concentration of $1.0 \pm 0.1$ ppbv, whereas in November and December, MTBE levels were in the range from below 0.1 to $1.9 \mathrm{ppbv}$, with an average concentration of $0.8 \pm 0.1$.

Table 1: MTBE's ambient air concentrations in San José, Costa Rica between October 17, 2005 and December 04, 2005.

\begin{tabular}{|c|c|c|c|}
\hline \multirow{2}{*}{$\begin{array}{c}\text { Date } \\
(2005)\end{array}$} & \multicolumn{3}{|c|}{ MTBE (ppbv) } \\
\cline { 2 - 4 } & Average (s.d.) $^{1}$ & Minimum & Maximum \\
\hline $10-17$ & $1.7(1.3)$ & 0.3 & 7.0 \\
\hline $10-18$ & $1.0(1.6)$ & $<0.1$ & 6.3 \\
\hline $10-19$ & $0.9(0.4)$ & 0.3 & 2.3 \\
\hline $10-20$ & $0.5(0.4)$ & $<0.1$ & 0.8 \\
\hline $11-21$ & $0.4(0.4)$ & $<0.1$ & 1.5 \\
\hline $11-22$ & $0.7(0.7)$ & $<0.1$ & 1.7 \\
\hline $11-23$ & $1.5(0.2)$ & 1.2 & 1.0 \\
\hline $11-24$ & $0.6(0.4)$ & $<0.1$ & 1.9 \\
\hline $11-25$ & $1.0(0.7)$ & 0.4 & 1.9 \\
\hline $11-26$ & $1.1(0.7)$ & 0.4 & 1.1 \\
\hline $11-27$ & $0.8(0.6)$ & $<0.1$ & 1.2 \\
\hline $11-28$ & $0.8(0.5)$ & $<0.1$ & 1.4 \\
\hline $11-29$ & $0.9(0.5)$ & 0.2 & 0.9 \\
\hline $11-30$ & $1.0(0.5)$ & 0.3 & 1.0 \\
\hline $12-01$ & $0.6(0.2)$ & 0.2 & 1.9 \\
\hline $12-02$ & $0.7(0.4)$ & 0.2 & 0.2 \\
\hline $12-03$ & $0.6(0.3)$ & 0.2 & \\
\hline $12-04$ & $0.8(0.5)$ & 0.2 & \\
\hline
\end{tabular}

${ }^{1}$ Standard deviation. 


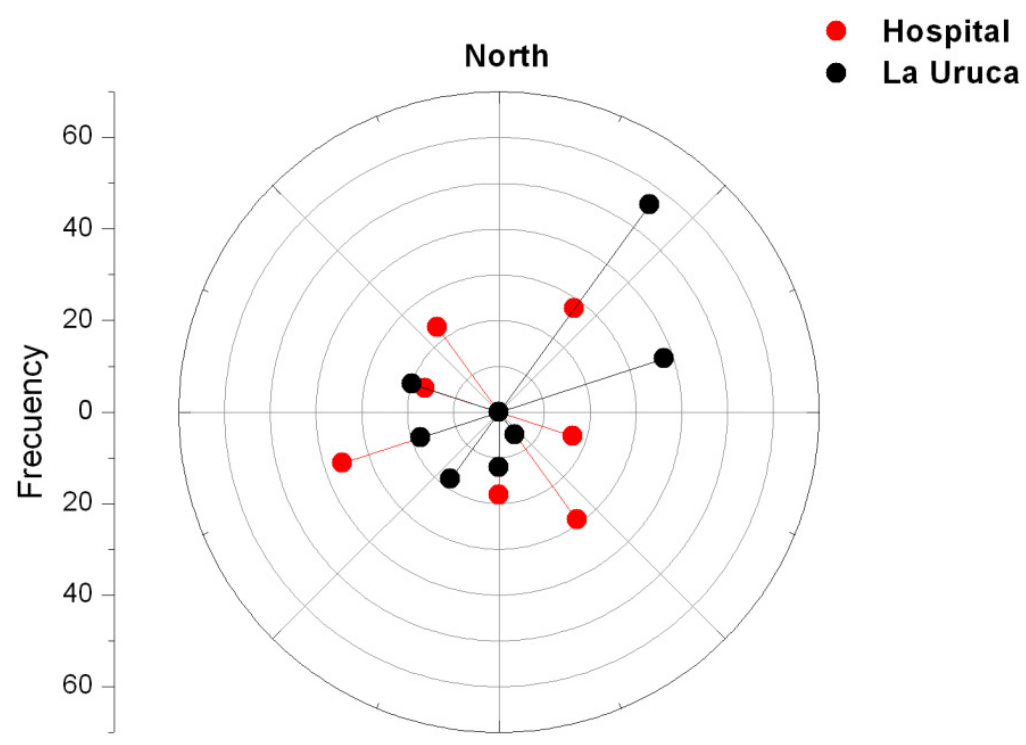

Figure 1: Wind roses for Hospital and La Uruca, between October 2005 and November-December 2005, respectively.

These average concentrations, expressed on mass per volume concentration units, corresponds to 3.6 and $2.9 \mu \mathrm{g} \mathrm{m}^{-3}$, which are useful to estimate relative human exposure to MTBE [9].

In general, MTBE ambient levels were higher in the rush hours in the morning, which indicates an influence of the vehicles emissions, as we will discuss next. During traffic hours at night, there is no evidence that vehicles emissions influenced the MTBE's ambient air concentrations. In order to investigate the origin of MTBE's emissions, an estimation of point sources of MTBE in San Jose was carried out according to a previous methodology used by Curren et al. [8]. Wind roses and pollutant roses were plotted to study the origin of MTBE at the two sampling locations (as shown in Figures 1 and 2). Meteorological data was obtained from the National Meteorology Institute, and from meteorological station located in downtown San Jose, approximately $2.5 \mathrm{~km}$ away from each sampling site. Hourly average wind direction was recorded along the sampling campaign and MTBE's concentrations were then assigned to the wind directions from October to December. In October the wind direction at Hospital was mainly from northwest, a typical situation during morning hours, with an average wind speed of $1.53 \mathrm{~m} \mathrm{~s}^{-1}$.

In November and December the wind direction at La Uruca was predominantly from northeast, a meteorological condition observed during these months because of the trade wind's influence. Average wind speed was $3.44 \mathrm{~m} \mathrm{~s}^{-1}$. The identified point sources near Hospital were a gas station, located 

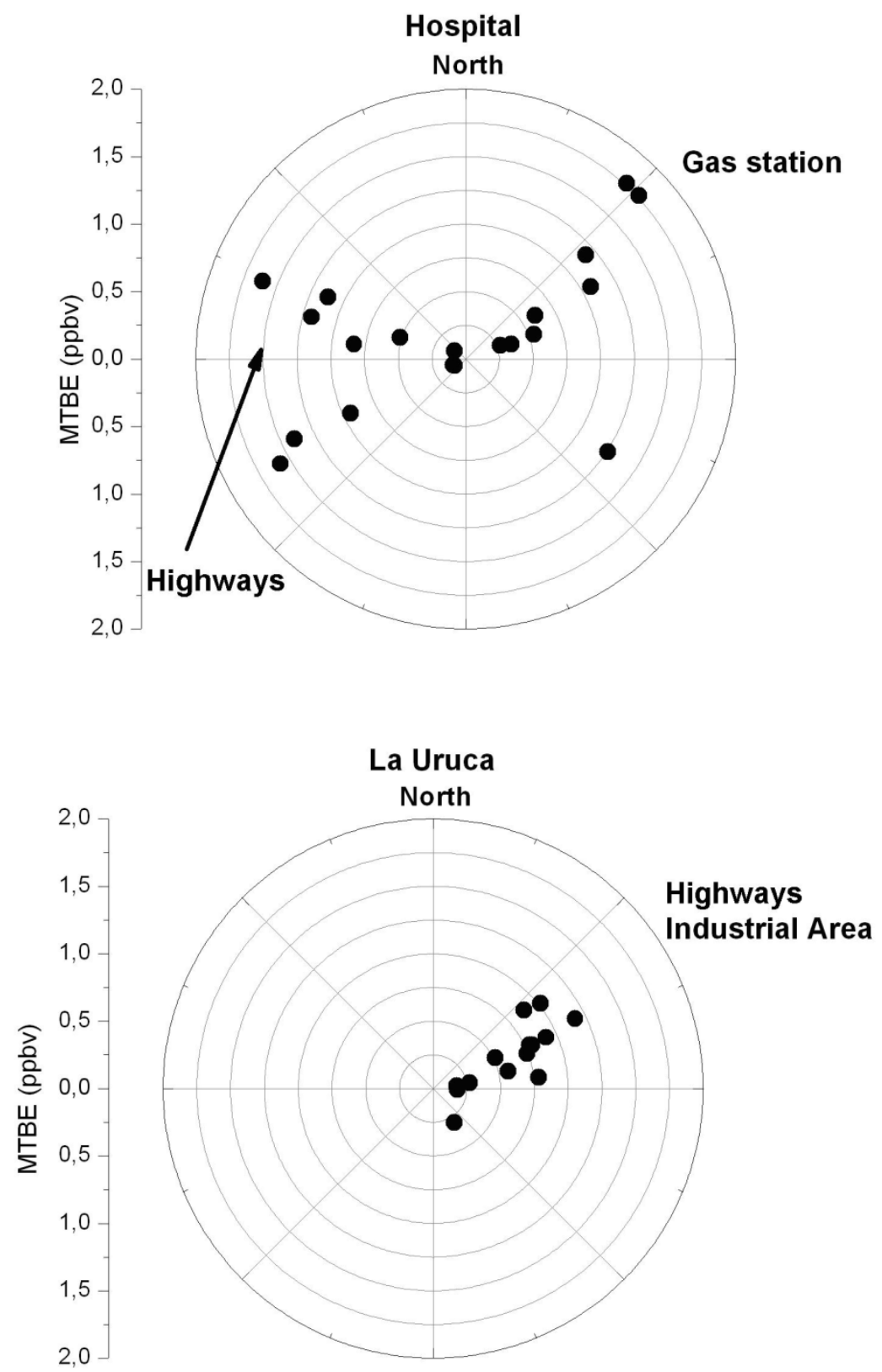

Figure 2: MTBE's ambient air concentrations and wind direction for La Uruca and Hospital, between October 2005 and December 2005, respectively. 
Table 2: Ambient air concentrations of MTBE reported at urban locations (1993-2004).

\begin{tabular}{|c|c|c|c|c|c|}
\hline \multirow{2}{*}{ Location } & \multirow{2}{*}{ Year } & \multirow{2}{*}{ Sampling duration } & \multicolumn{2}{|c|}{ MTBE (ppbv) } & \multirow{2}{*}{ Reference } \\
\cline { 4 - 5 } & & & Mean & Range & \\
\hline Houston, USA & 1993 & $24 \mathrm{~h}$ & 0.4 & $0.2-2.8$ & {$[10]$} \\
\hline Boston, USA & 1993 & $24 \mathrm{~h}$ & $<0.2$ & $<0.2-0.5$ & {$[10]$} \\
\hline SW Finland & 1998 & $8 \mathrm{~h}, 16 \mathrm{~h}^{1}$ & 2.6 & $0.3-14.4$ & {$[1]$} \\
\hline Porto Alegre, Brazil & 1998 & $1 \mathrm{~min}^{2}$ & 6.6 & $0.2-17.1$ & {$[9]$} \\
\hline Daegu, South Korea & 2004 & $24 \mathrm{~h}^{3}$ & 0.9 & $0.1-1.5$ & {$[11]$} \\
\hline
\end{tabular}

${ }^{1}$ Samples collected $50 \mathrm{~m}$ distance away from gas stations; ${ }^{2}$ Canister filling time; ${ }^{3}$ Geometric mean values reported for personal ambient air.

about $200 \mathrm{~m}$ away from sampling location, and a highway located south, which runs through an industrial zone too. At Hospital, it was not possible to identify an influence of wind direction during the entire sampling campaign. At La Uruca, the MTBE's sources could be attributed to a highway running northeast the sampling site, and to the fact that most part of the city is located upwind and east of this sampling location, which contributes to increase the MTBE levels in this site. MTBE's concentrations were clearly influenced by wind direction in this site. It was also noted that hourly mean MTBE's concentrations recorded in October were about three times higher than those values measured in November and December in both sampling points. This was attributed to the increment on the wind speed during these last two months.

When these measurements were made in San Jose, there was none information was available regarding levels of MTBE at urban locations in Central American cities. Because of this lack of information, it was needed to compare the concentrations of MTBE in San Jose with concentrations reported at other urban locations; this data is summarized in Table 2. According to the ambient concentrations of MTBE in San Jose, the listed information in Table 2 indicates that San Jose's levels are typical for urban areas, even though comparison was made only based on average values. In some parts of the world, gasoline with a high content of MTBE has been used (Porto Alegre, Brazil, for example), which was not the case for Costa Rica. This situation contributed to diminish the ambient air concentrations of this compound.

\section{Conclusions}

We estimated that ambient MTBE levels in San Jose, Costa Rica were related mainly to vehicles emissions, where identified point sources included highways located south and east San Jose, as well as a gas station located close the sampling location at Hospital. These point sources are typically present in urban areas, and using reference MTBE levels reported at other urban locations, MTBE concentrations in San Jose can be consider as representative to urban areas.

Further VOC measurements in San Jose, for longer periods of time and that include more sampling locations, are needed. This data can be related with the 
data available for inorganic species $\left(\mathrm{NO}_{x}, \mathrm{SO}_{2}, \mathrm{CO}\right)$, which will allow authorities to improve the understanding of the air pollution problem in San Jose. We also recommend including other matrices, such as groundwater and soil, as well as to include toxicological assessments in individuals that are exposed to petrol vapours during working hours (gas station workers, for example). According to the MTBE concentrations measured in San Jose, there is no experimental evidence demonstrating that these levels may be hazardous to people's health, although it could be a problem for pedestrians walking near gas stations [5].

\section{References}

[1] Vainiotalo, S., Y. Peltonen, P. Pfäffli. 1998. MTBE Concentrations in Ambient Air in the Vicinity of Service Stations. Atmospheric Environment, 32, pp. 3503-3509.

[2] Schade, G.W., G.B. Dreyfus, A.H. Goldstein. 2002. Atmospheric Methyl Tertiary Butyl Ether (MTBE) at a Rural Mountain Site in California. Journal of Environmental Quality, 31, pp. 1088-1094.

[3] Lee, C.W., S.N. Mohr, C.P. Weisel. 2001. Toxicokinetics of human exposure to methyl tertiary-butyl ether (MTBE) following short-term exposures. Journal of Exposure and Analytical Epidemiology, 11, pp. 6778.

[4] Fiedler, N., K.K. McNeil, S. Mohr, P. Lehrer, R.E. Opiekun, C.H. Lee, T. Wainman, R. Hamer, C. Weisel, R. Edelberg, P.J. Lioy. 2000. Controlled Human Exposure to Methyl Tertiary Butyl Ether in Gasoline: Symptoms, Psychophysiologic and Neurobehavioral Responses of Self-Reported Sensitive Persons. Environmental Health and Perspectives, 108, pp. 753763.

[5] Morales, J., Esquivel, G., Valdés, J. Paper G015. Aromatic Hydrocarbons near Gas Stations in Heredia, Costa Rica. 27th Latin American Congress on Chemistry and 6th International Congress on Chemistry and Chemical Engineering, La Havana, Cuba, October 16-20, 2006.

[6] Esquivel, G., Rodríguez, F., Valdés, J. Paper G023. Determination of Anthropogenic and Biogenic Hydrocarbons in Costa Rica. 27th Latin American Congress on Chemistry and 6th International Congress on Chemistry and Chemical Engineering, La Havana, Cuba, October 16-20, 2006.

[7] Löfgren, L., K. Perssen, A. M. Strömvall, G. Petersson. 1991. Exposure commuters to volatile aromatic hydrocarbons from petrol exhaust. Science of Total Environment, 108, pp. 225-233.

[8] Curren, K.C., Dann, T.F. Wang, D.K. 2006. Ambient air 1,3 butadiene in Canada (1995-2003): seasonal, day of week variations, trends and source influences. Atmospheric Environment, 40, pp. 170-181.

[9] Grosjean, E., D. Grosjean, R., Gunawardena, R.A., Rasmussen. 1998. Ambient concentrations of ethanol and methyl tert-butyl ether in Porto Alegre, Brazil. Environmental Science and Technology, 32, pp. 33713379. 
[10] Kelly, T.J., P.J. Callahan. 1993. Method Development and Field Measurements for Polar Volatile Organic Compounds in Ambient Air. Environmental Science and Technology, 27, pp. 1146-1153.

[11] Park, K.H., W.K. Jo. 2004. Personal volatile organic compound (VOC) exposure of children attending elementary schools adjacent to industrial complex. Atmospheric Environment, 38, pp. 1303-1313. 